\title{
Correction to: Roles of the Notch Signaling Pathway in Ovarian Functioning
}

\author{
Shuhan Guo ${ }^{1}$. Song Quan ${ }^{1} \cdot$ Siyi Zou ${ }^{1}$ \\ Published online: 12 July 2021 \\ (C) Society for Reproductive Investigation 2021
}

\section{Correction to: Reproductive Sciences} https://doi.org/10.1007/s43032-021-00610-6

This article was updated to correct the affiliation of author Song Quan.

Publisher's Note Springer Nature remains neutral with regard to jurisdictional claims in published maps and institutional affiliations.

The online version of the original article can be found at https://doi.org/ 10.1007/s43032-021-00610-6

$\triangle$ Song Quan

quansong@smu.edu.cn

1 Department of Obstetrics and Gynecology, Reproductive Medicine Center, Nanfang Hospital/The First School of Clinical Medicine, Southern Medical University, Guangzhou, China 